\title{
An Experimental Study to Evaluate Hypolipidemic Effect of Terminalia arjuna on High Fat Diet Induced Dyslipidaemia in Wistar Rat
}

\author{
Aaliya Bari, Shivangi Sharma, Rishi Pal, Amod Kumar Sachan, Rakesh Kumar Dixit and Rajendra Nath* \\ Department of Pharmacology \& Therapeutics, KGMU, India
}

Submission: February 05, 2020; Published: February 22, 2020

*Corresponding author: Rajendra Nath, Department of Pharmacology \&Therapeutics, King George's Medical University, Lucknow, U.P, 226003, India

Abstrcat

Introduction: Hyperlipidaemia is a well-established cardiovascular disease risk factor. Different medications are used to regulate dyslipidaemia. Efficacy and safety are questionable on treatment with lipid lowering drug for long period. Need of time is to search for new lead compound from phytoconstituents of plants which is equal in potency and efficacy with present oral hypolipidemic drug but with fewer side effects. Terminalia arjuna has hypolipidemic properties therefore this research is designed to evaluate the hypolipidemic effect of Terminalia arjuna on high-fat diet induced dyslipidaemia in Wistar rats.

Methods: An experimental study was done. Total 36 Wistar rats divided into 6 group randomly. Group I given normal pellet diet. In remaining group dyslipidaemia induced by high fat diet given for four weeks. Group II (dyslipidaemia control) was given high fat diet. Group III, IV were given Terminalia arjuna 250 and $500 \mathrm{mg} / \mathrm{kg}$ per oral and group V, VI were given Rosuvastatin $10 \mathrm{mg} / \mathrm{kg}$ and $20 \mathrm{mg} / \mathrm{kg}$ per oral for $8 \mathrm{weeks}$. Blood samples withdrawn by retro-orbital puncture and analysed for total cholesterol, triglycerides, HDL by commercial kits. LDL, VLDL calculated by friedewald formula. ANOVA followed by post hoc analysis used for statistical analysis.

Results: Terminalia arjuna showed reduction of total cholesterol, triglycerides, VLDL, LDL level at both doses and intergroup comparison were found to be statistically significant $(\mathrm{p}<0.05)$ at end of treatment. The change with Terminalia arjuna $(500 \mathrm{mg} / \mathrm{kg})$ in total cholesterol, triglycerides, VLDL, LDL was comparable with Rosuvastatin $(10 \mathrm{mg} / \mathrm{kg})$.

Conclusion: Terminalia arjuna has substantial Hypolipidemic activity as it decreases total cholesterol, triglycerides, VLDL, LDL in dyslipidaemia rat thus it has promising role in treatment of hyperlipidaemia.

Keywords: Rosuvastatin; Hyperlipidaemia; Triglyceride HMGcoA; HDL; LDL

\section{Introduction}

Cardiovascular disease is one of the major causes of mortality and morbidity worldwide. Hyperlipidaemia is defined as elevation of serum total cholesterol (TC) and/or triglyceride (TG) or reduced high-density lipoprotein (HDL) cholesterol [1]. It is one the major risk factor for cardiovascular diseases [2,3]. Coronary heart disease is closely related to hypercholesterolemia and hypertriglyceridemia [4]. Disorders of lipid can be classified as primary and secondary. Primary disease is idiopathic and secondary disease is due to environmental factors (sedentary lifestyle, high fat diet), medications (thiazide, $\beta$-blockers, progesterone, anabolic steroids etc.), diseases (hypothyroidism, diabetes mellitus type 2 , chronic kidney disease, etc.,). Type 2 diabetes is also associated with hyperlipidaemia not only with abnormal glucose utilization and insulin resistance. There is a variety of evidence to support the fact that effective treatment of dyslipidaemia decreases Cardiovascular disease morbidity and mortality. Therefore, a holistic approach is required which includes different ways of regulating lipid levels, addressing related metabolic disorders and risk factors which are modifiable such as diabetes, cigarette smoking, hypertension, and obesity.

Lifestyle modification can be the first step in reducing the level of cholesterol. There are various Anti-hyperlipidaemic agents which are used to lower cholesterol, but HMG Co-enzyme reductase inhibitors (statins) are the most popular and frequently used agents. Treatment of lipid abnormalities is generally continued throughout as a life of patient. Many patients stop taking their medication without consulting doctors. In addition, efficacy and safety are questionable on treatment with lipid lowering 


\section{Current Research in Diabetes \& Obesity Journal}

drug for long period. Statins produce variety of side effects like myalgia, myopathy, rhabdomyolysis new onset diabetes mellitus type $2[5,6]$. Henceforth, research is focused on medicinal herbs that are used in traditional medicine and have few side effects [7]. The need of the time is to search for new leads compound from phytoconstituents of a plant which is equal in potency and efficacy with the present hypolipidaemic drug but with fewer side effects. In this study, Terminalia arjuna is commonly known as Arjun. It is of family Combretaceae. Terminalia arjuna tree bark powder has hypolipidaemic properties [8]. Therefore, we have planned this study to evaluate hypolipidemic effect of Terminalia arjuna on high fat diet induced dyslipidaemia in Wistar rat.

\section{Materials and Methods}

\section{Animals}

Thirty-six male Wistar rats weighing 160-180 grams were procured from CSIR-IITR, Lucknow (UP), India. The animals were housed in Institutional animal house under standard conditions of housing, that is, room temperature of $24-27^{\circ} \mathrm{C}$ and humidity of $60-65 \%$ with 12 -hour light and dark cycle. The food was given in the form of dry pellets and water was available ad libitum. Study was commenced after taking approval by the Institutional ethical committee of King George's Medical University Lucknow, India (Project no. 117/IAEC/2019).

\section{Description of diet}

Normal chow diet and high-fat diet (HFD) were procured from Bharat Science Solution Company, Lok Nagar, Unnao, Uttar Pradesh. High fat diet contained powdered Normal Pellet Diet $(365 \mathrm{~g} / \mathrm{kg})$, Lard $(310 \mathrm{~g} / \mathrm{kg})$, Caesin $(250 \mathrm{~g} / \mathrm{kg})$, Cholesterol $(10 \mathrm{~g} /$ $\mathrm{kg})$, Vitamin and mineral mix $(60 \mathrm{~g} / \mathrm{kg})$.

\section{Chemicals and drugs}

Terminalia arjuna bark extract (as dry powder) was procured from AGHP Enterprises,31, L.B. Road Thiruvanmiyur, Chennai-41. The drug was administered in a dose of 250 and $500 \mathrm{mg} / \mathrm{kg}$ body weight [9]. It was administered per orally, after dissolving it in distilled water, with the help of a cannula (gavage tube). Rosuvastatin (as a tablet) was procured from USV Private limited and was given in a dose of $10 \mathrm{mg} / \mathrm{kg}$ body weight $[10,11]$ and $20 \mathrm{mg} / \mathrm{kg}$ body weight [12] per orally after dissolving in DMSO. Drugs were administered per orally with the help of a cannula (gavage tube).

\section{Experimental design}

The Wistar rats were given four weeks to acclimatize to the environment of the animal house. Total thirty-six Wistar rats were used in the study and they were randomly divided into six groups with six rats in each group. As a normal control group, six rats were fed on a normal diet. The other thirty rats were then fed with high fat diet and water for four weeks. After that for an eight-week period, animals were grouped and handled as follows. High fat diet was given to the dyslipidaemic rats throughout the study.
Group I: Normal Control rats fed with normal pellet diet.

Group II: Dyslipidaemic control rats fed with high fat diet

Group III: Dyslipidaemic rats administered per orally with Terminalia arjuna bark extract (250mg/kg body weight).

Group IV: Dyslipidaemic rats administered per orally with Terminalia arjuna bark extract (500 mg/kg body weight).

Group V: Dyslipidaemic rats administered per orally with Rosuvastatin (10 mg/kg body weight).

Group VI: Dyslipidaemic rats administered per orally with Rosuvastatin (20 mg/kg body weight).

\section{Measurement of lipid profile levels}

A biochemical analyser manufactured Vital scientific N.V. Netherlands was used to evaluate the amount of total cholesterol (TC), triglyceride (TG), high density lipoprotein cholesterol (HDL-C). LDL-C and VLDL-C was calculated by the Friedewald equation:

$$
\begin{gathered}
\operatorname{LDL}\left(\frac{\mathrm{mg}}{\mathrm{dl}}\right)=\left(\text { Total Cholesterol- } \frac{\text { Triglycerides }}{5}\right) \times \mathrm{HDL} \\
\operatorname{VLDL}\left(\frac{\mathrm{mg}}{\mathrm{dl}}\right)=\frac{\text { Triglycerides }}{5}
\end{gathered}
$$

\section{Statistical analysis}

All data were expressed as mean \pm SD for six rats in each group. One-way analysis of variance (ANOVA) followed by Tukey's test was used for statistical analysis. It was carried out using SPSS software package, version 21.0. $\mathrm{p}$ value $<0.05$ was considered as significant.

\section{Results}

\section{Effect on total cholesterol}

Table 1: Between Group Differences (Tukey HSD Test): Total cholesterol.

\begin{tabular}{|c|c|c|}
\hline \multirow{2}{*}{ Between Group } & \multicolumn{2}{|c|}{ At the End of 13 th $^{\text {th }}$ Week } \\
\cline { 2 - 3 } & Mean Difference & 'p' \\
\hline Group I vs. Group II & -61.94 & $<0.001^{*}$ \\
\hline Group II vs. Group III & 25.1 & $<0.001^{*}$ \\
\hline Group II vs. Group IV & 37.11 & $<0.001^{*}$ \\
\hline Group II vs. Group V & 41.41 & $<0.001^{*}$ \\
\hline Group II vs. Group VI & 56.6 & $<0.001^{*}$ \\
\hline Group III vs. Group V & 16.31 & $0.006^{*}$ \\
\hline Group III vs. Group VI & 31.5 & $<0.001^{*}$ \\
\hline Group IV vs. Group V & 4.29 & 0.963 \\
\hline Group IV vs. Group VI & 19.48 & $0.001^{*}$ \\
\hline
\end{tabular}

${ }^{*} \mathrm{p}$-value less than 0.05 is significant 


\section{Current Research in Diabetes \& Obesity Journal}

At 13 weeks, maximum total cholesterol levels were observed in Group II $(166.30 \pm 5.16 \mathrm{mg} / \mathrm{dl})$ followed by Group III $(141.17 \pm 7.44 \mathrm{mg} / \mathrm{dl})$ while minimum total cholesterol were observed in Group I $(104.32 \pm 10.00 \mathrm{mg} / \mathrm{dl})$ followed by Group VI $(109.67 \pm 3.30 \mathrm{mg} / \mathrm{dl})$ then in Group V $(124.86 \pm 5.11 \mathrm{mg} / \mathrm{dl})$, results are summarized in Figure 1. Intergroup difference in total cholesterol levels of above groups was found to be significant. On exploring the between group differences, it was observed that Group IV \& V had comparable total cholesterol levels (Table I).

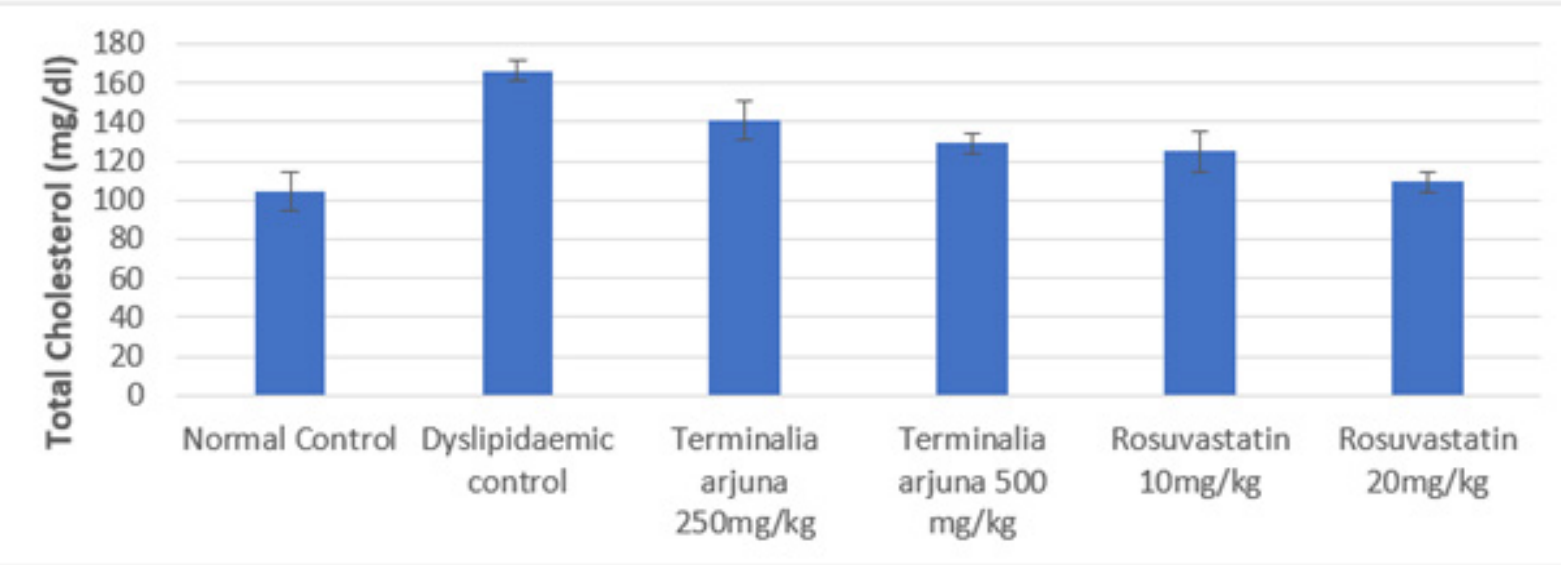

Figure 1: Mean Total cholesterol \pm SD

\section{Effect on triglycerides}

At 13 weeks, minimum Triglyceride levels were observed in Group I $(76.15 \pm 7.06 \mathrm{mg} / \mathrm{dl})$ followed by Group VI $(83.52 \pm 3.87$ $\mathrm{mg} / \mathrm{dl})$ Group V $(89.27 \pm 4.37 \mathrm{mg} / \mathrm{dl})$ while maximum Triglyceride levels were observed in Group II $(194.37 \pm 6.82 \mathrm{mg} / \mathrm{dl})$ followed by Group III (129.81 \pm 4.84 mg/dl) and Group IV (95.33 $\pm 4.93 \mathrm{mg} /$ $\mathrm{dl})$, results are summarized in Figure 2. Intergroup difference for Triglyceride levels of above eight groups was found to be significant. On exploring the between group differences, Group IV \& V had comparable triglyceride levels (Table 2).

Table 2: Between Group Differences (Tukey HSD Test): Triglycerides.

\begin{tabular}{|c|c|c|}
\hline \multirow{2}{*}{ Between Group } & \multicolumn{2}{|c|}{ At the End of 13 ${ }^{\text {th }}$ Week } \\
\cline { 2 - 3 } & Mean Difference & 'p' \\
\hline Group I vs. Group II & -118.22 & $<0.001^{*}$ \\
\hline Group II vs. Group III & 64.56 & $<0.001^{*}$ \\
\hline Group II vs. Group IV & 99.05 & $<0.001^{*}$ \\
\hline Group II vs. Group V & 105.11 & $<0.001^{*}$ \\
\hline Group II vs. Group VI & 110.86 & $<0.001^{*}$ \\
\hline Group III vs. Group V & 40.55 & $<0.001^{*}$ \\
\hline Group III vs. Group VI & 46.3 & $<0.001^{*}$ \\
\hline Group IV vs. Group V & 6.06 & 0.609 \\
\hline Group IV vs. Group VI & 11.81 & $0.020^{*}$ \\
\hline
\end{tabular}

${ }^{*} \mathrm{p}$-value less than 0.05 is significant.

\section{Effect on high density lipoproteins}

At 13 weeks, minimum HDL levels were observed in Group II $(32.23 \pm 5.40 \mathrm{mg} / \mathrm{dl})$ followed by Group III \& IV $(40.17 \pm 4.19$ \& $40.98 \pm 2.71 \mathrm{mg} / \mathrm{dl}$ ) while maximum HDL levels were observed in Group I $(46.14 \pm 4.60 \mathrm{mg} / \mathrm{dl})$ followed by Group VI and V (45.30 $\pm 7.67 \& 45.03 \pm 6.26 \mathrm{mg} / \mathrm{dl}$ respectively), results are summarized in Figure 3. Intergroup difference was found to be significant. On exploring the between group differences Group II had significantly lower HDL levels as compared to Group I (Table 3).

Table 3: Between Group Differences (Tukey HSD Test): HDL.

\begin{tabular}{|c|c|c|}
\hline \multirow{2}{*}{ Between Group } & \multicolumn{2}{|c|}{ At the end of $\mathbf{1 3}^{\text {th }}$ week } \\
\cline { 2 - 3 } & Mean difference & 'p' \\
\hline Group I vs. Group II & 13.91 & $0.001^{*}$ \\
\hline Group II vs. Group III & -7.94 & 0.171 \\
\hline Group II vs. Group IV & -8.75 & 0.097 \\
\hline Group II vs. Group V & -12.8 & $0.003^{*}$ \\
\hline Group II vs. Group VI & -13.07 & $0.002^{*}$ \\
\hline
\end{tabular}

${ }^{*} p$-value less than 0.05 is significant.

\section{Effect on low density lipoproteins (LDL) level}

At 13 weeks, minimum LDL level was observed in Group I $(42.95 \pm 4.50 \mathrm{mg} / \mathrm{dl})$ followed by Group VI $(47.66 \pm 9.68 \mathrm{mg} / \mathrm{dl})$ and Group V $(61.97 \pm 9.04 \mathrm{mg} / \mathrm{dl})$ while maximum LDL level was 


\section{Current Research in Diabetes \& Obesity Journal}

observed in Group II $(95.16 \pm 9.66 \mathrm{mg} / \mathrm{dl})$ followed by Group III $(75.04 \pm 7.45 \mathrm{mg} / \mathrm{dl})$ and Group IV $(69.11 \pm 5.04 \mathrm{mg} / \mathrm{dl})$, results are summarized in Figure 4. On comparing the intergroup difference was found to be significant. On exploring between group differences, comparable LDL levels were found in Group III \& V, IV \& V had comparable LDL level (Table 4).

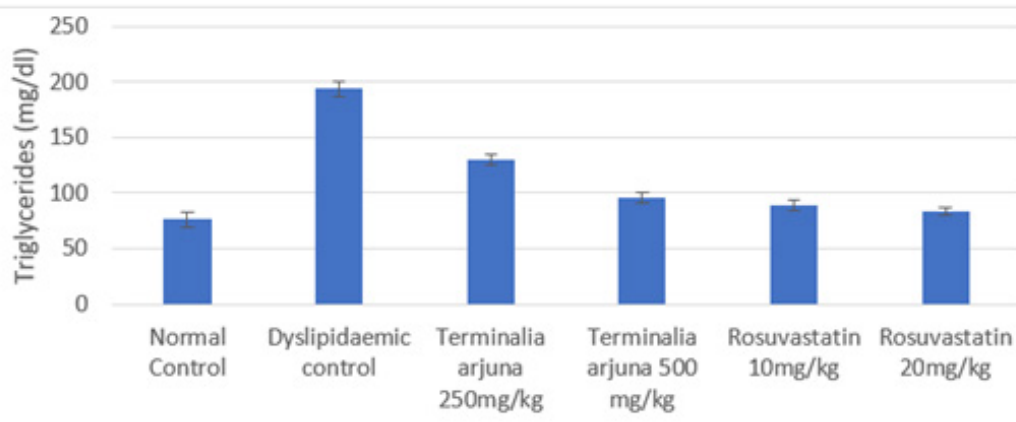

Figure 2: Mean Triglycerides \pm SD

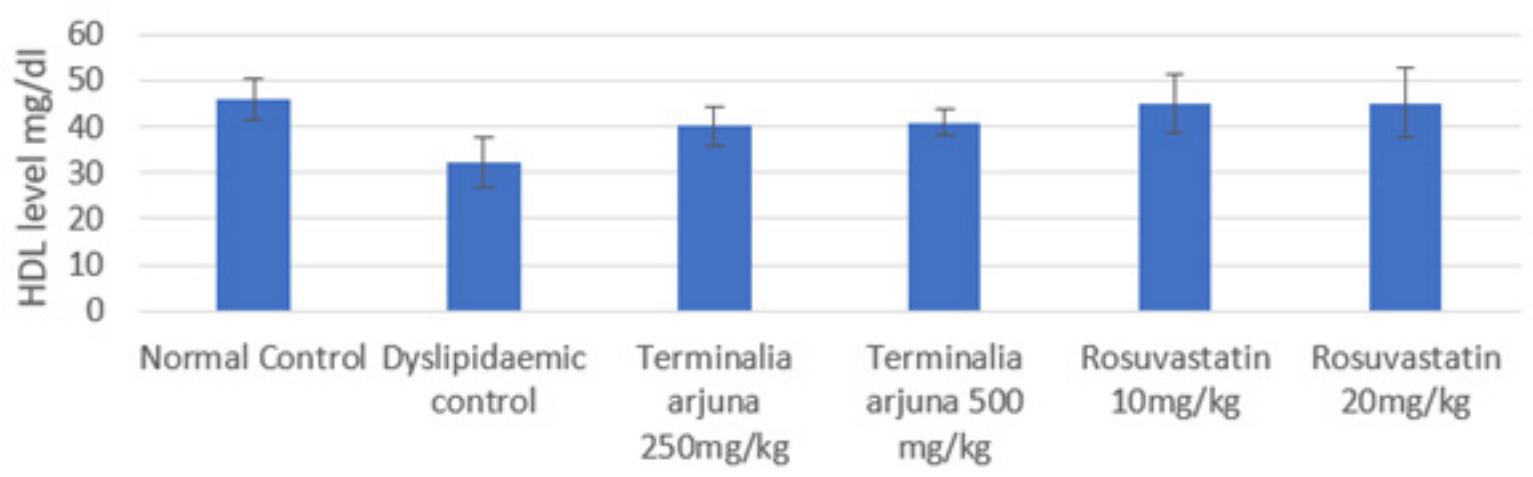

Figure 3: Mean High density lipoproteins $(H D L) \pm S D$.

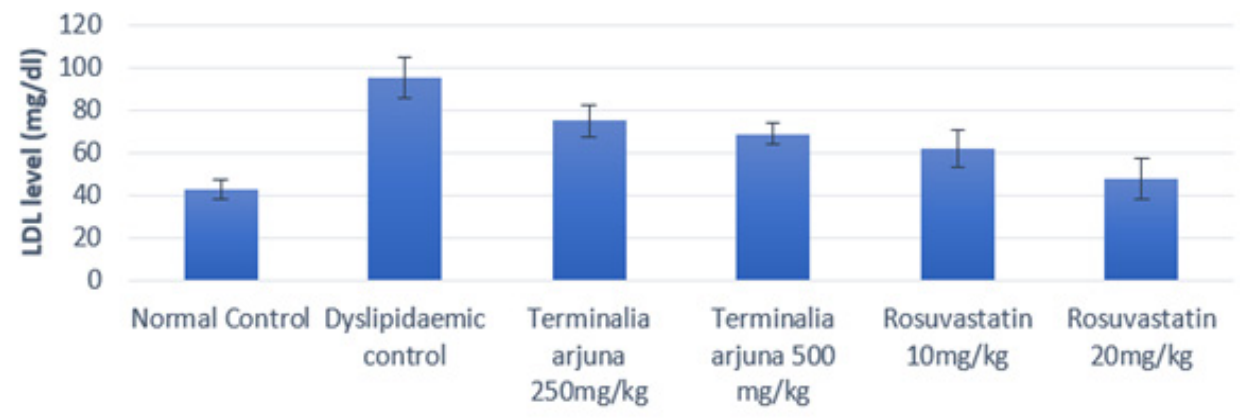

Figure 4: Mean Low density lipoproteins $(L D L) \pm S D$. 


\section{Current Research in Diabetes \& Obesity Journal}

Table 4: Between Group Differences (Tukey HSD Test): LDL.

\begin{tabular}{|c|c|c|}
\hline \multirow{2}{*}{ Between Group } & \multicolumn{2}{|c|}{ At the End of 13 th $^{\text {th }}$ Week } \\
\cline { 2 - 3 } & Mean difference & 'p' \\
\hline Group I vs. Group II & -52.21 & $<0.001^{*}$ \\
\hline Group II vs. Group III & 20.12 & $0.004^{*}$ \\
\hline Group II vs. Group IV & 26.05 & $<0.001^{*}$ \\
\hline Group II vs. Group V & 33.19 & $<0.001^{*}$ \\
\hline Group II vs. Group VI & 47.5 & $<0.001^{*}$ \\
\hline Group III vs. Group V & 13.06 & 0.152 \\
\hline Group III vs. Group VI & 27.37 & $<0.001^{*}$ \\
\hline Group IV vs. Group V & 7.13 & 0.816 \\
\hline Group IV vs. Group VI & 21.44 & $0.002^{*}$ \\
\hline
\end{tabular}

${ }^{*} \mathrm{p}$-value less than 0.05 is significant.
Table 5: Between Group Differences (Tukey HSD Test): VLDL.

\begin{tabular}{|c|c|c|}
\hline \multirow{2}{*}{ Between Group } & \multicolumn{2}{|c|}{ At the End of $\mathbf{1 3}^{\text {th }}$ Week } \\
\cline { 2 - 3 } & Mean Difference & 'p' \\
\hline Group I vs. Group II & -23.65 & $<0.001^{*}$ \\
\hline Group II vs. Group III & 12.91 & $<0.001^{*}$ \\
\hline Group II vs. Group IV & 19.81 & $<0.001^{*}$ \\
\hline Group II vs. Group V & 21.02 & $<0.001^{*}$ \\
\hline Group II vs. Group VI & 22.17 & $<0.001^{*}$ \\
\hline Group III vs. Group V & 8.11 & $<0.001^{*}$ \\
\hline Group III vs. Group VI & 9.26 & $<0.001^{*}$ \\
\hline Group IV vs. Group V & 1.21 & 0.608 \\
\hline Group IV vs. Group VI & 2.36 & $0.020^{*}$ \\
\hline
\end{tabular}

${ }^{*}$-value less than 0.05 is significant.

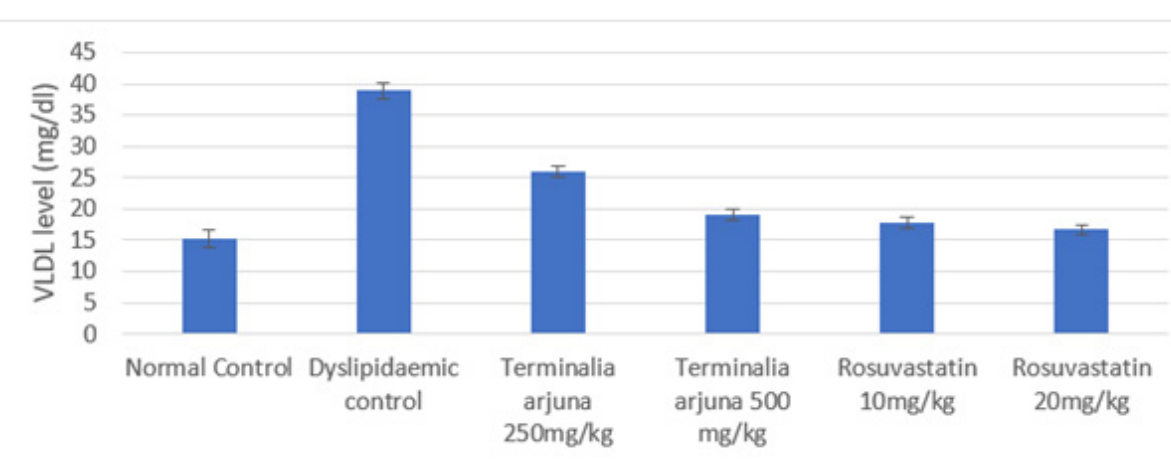

Figure 5: Mean Very Low-Density Lipoproteins $(V L D L) \pm S D$.

\section{Effect on very low-density lipoproteins}

At 13 weeks, minimum VLDL level was observed in Group I $(15.23 \pm 1.41 \mathrm{mg} / \mathrm{dl})$ followed by Group VI $(16.70 \pm 0.77 \mathrm{mg} / \mathrm{dl})$ and Group V $(17.85 \pm 0.87 \mathrm{mg} / \mathrm{dl})$ while maximum VLDL level was observed in Group II $(38.88 \pm 1.37 \mathrm{mg} / \mathrm{dl})$ followed by Group III $(25.96 \pm 0.97 \mathrm{mg} / \mathrm{dl})$ and Group IV $(19.07 \pm 0.99 \mathrm{mg} / \mathrm{dl})$, results are summarized in Figure 5. On comparing the intergroup difference was found to be significant, on exploring between group differences, comparable LDL levels were found in Group IV \& V (Table 5).

\section{Discussion}

Though, there has been considerable progress in medical science, still, there is an increase in metabolic disorders like diabetes, hypertension, obesity, and dyslipidaemia. The prevalence of these diseases is increasing at an alarming pace. Several drugs are available to either prevent or cure these diseases, but they are associated with numerous adverse effects and are a cause of financial distress to the patient because of their heavy cost. Hence, it is the dire need of the hour to look for other cheaper and safer alternatives for prevention and cure of these chronic diseases.
Plants have been an important source of herbal medicines since times immemorial. These herbal drugs have the advantage of being efficacious, with least side effects and affordable cost. Terminalia arjuna is one such herb, which has been known to be used for the treatment of a few diseases for ages, in Ayurvedic and Unani system of medicine. Thus, it seems prudent to explore its anti-hyperlipidaemic activity in dyslipidaemic rats. At 13 th week there increase in TC, TG, LDL, VLDL in untreated diabetic group II as compared with normal rat group I and it was statistically significant $(\mathrm{p}<0.001)$. There was decrease in mean TC, TG, VLDL, LDL level of group III, IV, V, VI as compared to untreated diabetic group II and it was statistically significant $(\mathrm{p}<0.05)$. Group IV (Terminalia arjuna $500 \mathrm{mg} / \mathrm{kg}$ ) showed reduction almost like Group V (Rosuvastatin $10 \mathrm{mg} / \mathrm{kg}$ ) in TC, TG, VLDL, LDL and it was comparable. This suggests that Terminalia arjuna in dose of $500 \mathrm{mg} / \mathrm{kg}$ is better anti hyperlipidaemic drug. Terminalia arjuna in a dose of $500 \mathrm{mg} / \mathrm{kg}$ has similar effect to Rosuvastatin in a dose of $10 \mathrm{mg} / \mathrm{kg}$.

At $13^{\text {th }}$ week HDL level was found to decreased in Group II (untreated diabetic rat) as compared to group I normal rat and it was found to be statistically significant $(\mathrm{p}<0.001)$. When 
compared with group II (diabetic rat), highest increase in HDL level was found in group VI (Rosuvastatin $20 \mathrm{mg} / \mathrm{kg}$ ) then in group V (Rosuvastatin $10 \mathrm{mg} / \mathrm{kg}$ ) this increase was found to be statistically significant $(\mathrm{p}<0.05)$. Group III, IV (Terminalia arjuna $250 \& 500 \mathrm{mg} / \mathrm{kg}$ ) both increased the HDL level, but it was not found to be statistically significant. It may be because HDL takes times to increase and we need study with longer duration of time. The previous studies are in accordance with my finding when we are comparing total cholesterol and triglycerides, VLDL, LDL but not HDL level. HDL take more time to increase and, in my study, it is in increasing trend but not significant, it may be due to small duration of study. Ragavan et al. (2006) reported that Terminalia arjuna decreased TC, TG, VLDL, LDL at both the dose 250 and $500 \mathrm{mg} / \mathrm{kg}$ body weight and the dose of $500 \mathrm{mg} / \mathrm{kg}$ body weight showed more effect [9].

Patil et al. (2011) also reported that there was decrease in total cholesterol, triglycerides, LDL, VLDL and increase in HDL level on treatment with Terminalia arjuna [13]. Alam et al. (2011) demonstrated that Terminalia arjuna have potential lipid lowering effect in type 2 diabetic rats. Arjunic acid as well as its derivatives undergoes biotransformation by hepatic drug metabolism and thus metabolites which are formed is responsible for lipid lowering activity [14]. Nigam et al. (2008) reported in his study that Rosuvastatin decreased the TC, TG, VLDL, LDL and increased the HDL level in rats with high TC, TG, LDL, VLDL level [15]. It is suspected that lipid-lowering action is mediated by increasing hepatic cholesterol clearance, lipogenic enzyme downregulation, and HMG-CoA reductase enzyme inhibition [16]. High concentrations of fibre, starch, tannin, beta-sitosterol, calcium and sodium carbonates and aglycones- arjunin, arjunolic acid and arjunoside I, II, III and IV are found in the bark, resulting in reduced absorption of fat from the intestines [17].

\section{Conclusion}

Keeping in view of the results obtained in the present study, the following conclusions may be drawn that Terminalia arjuna also has significant effect on decreasing total cholesterol, triglycerides, LDL and VLDL in the dyslipidaemic rats which is dose dependent but does not have any significant effect on increasing HDL levels. This effect is also more pronounced at high dose of Terminalia arjuna $500 \mathrm{mg} / \mathrm{kg}$. The present study is encouraging and may reveal the importance of Terminalia arjuna as an economical hypolipidemic agent with minimal or no side effects. These results also encourage the view that Terminalia arjuna can be used alone or as an add on therapy in treatment of dyslipidaemia. Therefore, more specific, and longer duration experimental and clinical studies are required to further substantiate the finding of present study.

\section{Acknowledgment}

I would like to thank statistician Mr. Tarun Arora for his support. I also want to thank the laboratory technician Mr. Ashok
Kumar and Lab attendant Mr. Shyam of my department for their support and help.

\section{References}

1. Munshi RP, Joshi SG, Rane BN (2014) Development of an experimental diet model in rats to study hyperlipidemia and insulin resistance, markers for coronary heart disease. Indian J Pharmacol 46(3): 270276.

2. Suanarunsawat T, Devakul Na Ayutthaya W, Songsak T, Thirawarapan $S$, Poungshompoo S (2011) Lipid-lowering and antioxidative activities of aqueous extracts of Ocimum sanctum L. leaves in rats fed with a highcholesterol diet. Oxid Med Cell Longev 962025.

3. Kong X, Gao Y, Geng X, Xie G, Hao S, Li Y, et al. (2018) Effect of lipid lowering tablet on blood lipid in hyperlipidemia model rats. Saudi J Biol Sci 25(4): 715-718.

4. Thompson GR (2004) Management of dyslipidaemia. Heart (90): 949955.

5. Barylski M, Nikolic D, Banach M, Toth P, Montalto G, et al. (2014) Statins and New-Onset Diabetes. Curr Pharm Des 20(22): 3657-3664.

6. Toth PP, Patti AM, Giglio RV, Nikolic D, Castellino G, et al. (2018) Management of Statin Intolerance in 2018: Still More Questions Than Answers. Am J Cardiovasc Drugs 18: 157-173.

7. WHO (2019) Traditional, complementary and integrative medicine.

8. Subramaniam S, Subramaniam R, Rajapandian S, Uthrapathi $S$, Gnanamanickam VR, Dubey GP (2011) Anti-Atherogenic Activity of Ethanolic Fraction of Terminalia arjuna Bark on Hypercholesterolemic Rabbits. Evid Based Complement Alternat Med 487916.

9. Ragavan B, Krishnakumari S (2006) Antidiabetic effect of T. arjuna bark extract in alloxan induced diabetic rats. Indian J Clin Biochem 21(2): 123-128.

10. Venisetty R, Rondi S, Peddolla R (2014) Neuro, cardio, and reno protective activities of rosuvastatin in streptozotocin-induced type 2 diabetic rats undergoing treatment with metformin and glimepiride. J Adv Pharm Technol Res 5(2): 78.

11. Hussein MMA, Mahfouz MK (2016) Effect of resveratrol and rosuvastatin on experimental diabetic nephropathy in rats. Biomed Pharmacother 82: 685-692.

12. Nangle MR, Cotter MA, Cameron NE (2003) Effects of rosuvastatin on nitric oxide-dependent function in aorta and corpus cavernosum of diabetic mice: Relationship to cholesterol biosynthesis pathway inhibition and lipid lowering. Diabetes 52(9): 2396-2402.

13. Patil RH, Prakash K, Maheshwari VL (2011) Hypolipidemic effect of Terminalia arjuna (L.) in experimentally induced hypercholesteremic rats. Acta Biologica Szegediensis 55(2).

14. Alam Morshed M, Haque A, Rokeya B, Ali L (2011) Antihyperglycemic and Lipid lowering effect of Terminalia arjuna bark extract on Streptozotocin indiced Type 2 Diabetic Model Rats. Int J Pharm Pharm Sci 3(4): 449-453.

15. Nigam GK, Ansari MN, Bhandari U (2008) Effect of rosuvastatin on methionine-induced hyperhomocysteinaemia and haematological changes in rats. Basic Clin Pharmacol Toxicol 103(3): 287-292.

16. Dwivedi S, Chopra D (2014) Revisiting terminalia arjuna-an ancient cardiovascular drug. J Tradit Complement Med 4(4): 224-231.

17. Ram A, Lauria P, Gupta R, Kumar P, Sharma VN (1997) Hypocholesterolaemic effects of Terminalia arjuna tree bark. J Ethnopharmacol 55(3): 165-169. 
This work is licensed under Creative Commons Attribution 4.0 Licen

DOI: 10.19080/CRDOJ.2021.14.5582

\begin{tabular}{l} 
Your next submission with Juniper Publishers \\
will reach you the below assets \\
- Quality Editorial service \\
- Swift Peer Review \\
- Reprints availability \\
- E-prints Service \\
- Manuscript Podcast for convenient understanding \\
- Global attainment for your research \\
- Manuscript accessibility in different formats \\
( Pdf, E-pub, Full Text, Audio) \\
- Unceasing customer service \\
Track the below URL for one-step submission \\
https://juniperpublishers.com/online-submission.php \\
\hline
\end{tabular}

